OPEN ACCESS

Edited by:

Dana Kristjansson

Norwegian Institute of Public Health

(NIPH), Norway

Reviewed by:

Marilyn Klug,

University of North Dakota,

United States

Sungshim Lani Park,

University of Hawaii at Manoa,

United States

*Correspondence:

Ya-Guang Fan

fanyaguang75@163.com

Fang-Hui Zhao

zhaofangh@cicams.ac.cn

Specialty section:

This article was submitted to

Cancer Epidemiology and Prevention,

a section of the journal

Frontiers in Oncology

Received: 17 November 2021 Accepted: 28 January 2022

Published: 01 March 2022

Citation:

Su Z, Jia X-H, Zhao F-H, Zhou Q-H, Fan Y-G and Qiao Y-L (2022) Effect of

Time Since Smoking Cessation on Lung

Cancer Incidence: An Occupational

Cohort With 27 Follow-Up Years.

Front. Oncol. 12:817045.

doi: 10.3389/fonc.2022.817045

\section{Effect of Time Since Smoking Cessation on Lung Cancer Incidence: An Occupational Cohort With 27 Follow-Up Years}

\author{
Zheng Su ${ }^{1}$, Xin-Hua Jia ${ }^{1,2}$, Fang-Hui Zhao ${ }^{1 *}$, Qing-Hua Zhou ${ }^{3,4}$, Ya-Guang Fan ${ }^{4 *}$ \\ and You-Lin Qiao ${ }^{5}$
}

${ }^{1}$ Department of Epidemiology, National Cancer Center/National Clinical Research Center for Cancer/Cancer Hospital, Chinese Academy of Medical Sciences and Peking Union Medical College, Beijing, China, 2 The State Key Laboratory of Molecular Vaccinology and Molecular Diagnostics, National Institute of Diagnostics and Vaccine Development in Infectious Diseases, School of Public Health, Xiamen University, Xiamen, China, ${ }^{3}$ Sichuan Lung Cancer Institute, Sichuan Lung Cancer Center, West China Hospital, Sichuan University, Chengdu, China, ${ }^{4}$ Tianjin Key Laboratory of Lung Cancer Metastasis and Tumor Microenvironment, Tianjin Lung Cancer Institute, Tianjin Medical University General Hospital, Tianjin, China, ${ }^{5}$ Center for Global Health, School of Population Medicine and Public Health Chinese Academy of Medical Sciences \& Peking Union Medical College, Beijing, China

Background: This special cohort reveals the effect of smoking cessation in occupational miners exposed to radon and arsenic.

Methods: A total of 9,134 tin miners with at least 10 years of underground radon and arsenic exposure were enrolled beginning in 1992 and followed for up to 27 years. Detailed smoking information was collected at baseline, and information on smoking status was consecutively collected from 1992 to 1996. The Cox proportional hazards model was used to explore the relationship between time since smoking cessation and lung cancer.

Results: A total of 1,324 lung cancer cases occurred in this cohort over 167,776 personyears of follow-up. Among populations exposed to radon and arsenic, miners after quitting smoking for 10 years or more had almost halved their lung cancer risk [adjusted hazard ratio $(H R)=0.55,95 \% \mathrm{Cl}$ : 0.38-0.79], compared with current smokers. Among miners after quitting smoking for 5 years or more, lung cancer incidence approximately halved $(\mathrm{HR}=0.52,95 \% \mathrm{Cl}: 0.30-0.92)$ for squamous cell lung carcinoma, while it showed no significant decline for adenocarcinoma $(H R=0.79,95 \% \mathrm{Cl}$ : 0.34-1.85).

Conclusion: Smoking cessation for 10 years or more halved lung cancer incidence among miners exposed to radon and arsenic, and the benefit was more pronounced among squamous cell lung carcinoma.

Keywords: smoking cessation, lung cancer, cohort, radon, arsenic 


\section{WHAT THIS PAPER ADDS}

What is already known about this subject?

Preliminary studies suggest that there exist joint effects between radon, arsenic, and smoking. Quitting smoking reduces not only smoking-related lung cancer, but also smoking-radon- and smoking-arsenic-related lung cancer. However, there is no prospective cohort to report the effect of years of smoking cessation on lung cancer incidence among miners exposed to radon and arsenic.

What are the new findings?

Among miners exposed to radon and arsenic, smoking cessation of at least 10 years would halve lung cancer incidence, and the benefit was more related to squamous cell lung carcinoma.

How might it impact policy in the foreseeable future?

To reduce the burden of lung cancer, smoking cessation is urgently needed among radon and arsenic miners. The longer years of smoking cessation should be emphasized among occupational miners than the general population.

\section{BACKGROUND}

Lung cancer remains the most common cancer with respect to both incidence and mortality, both in China and throughout the world $(1,2)$. Tobacco smoking is the leading risk factor for lung cancer, but other factors related to lung cancer include environmental tobacco smoke, air pollution, occupational exposures, marijuana, and other recreational drugs (3-6). Either radon or arsenic exposure is evident to be the major occupational carcinogens of lung cancer concluded by the International Agency for Research on Cancer $(7,8)$.

While it is clear that smoking cessation reduces lung cancer risk in general populations, this topic has been rarely investigated in occupational epidemiological studies. Population-based studies suggested a sharp decrease in lung cancer risk for over $50 \%$ in the first 5 years after smoking cessation $(9,10)$. However, findings from general populationbased studies may not be directly generalized to occupational studies, because occupational workers additionally exposed to lung carcinogens generally have a higher lung cancer risk, and there exists a joint effect between cigarette use and occupational agents such as radon and arsenic. Consequently, the effect of smoking cessation on lung cancer tends to need a much longer time in occupational groups. A historical cohort of Chinese silicotics revealed that smoking cessation for 10 years halved lung cancer mortality among silicotics (11). Similarly, an asbestos-exposed cohort showed that lung cancer mortality rate ratio dropped steeply (over 50\%) during the first 10 years after quitting smoking (12).

Globally, no studies to date have reported the effect of smoking cessation on lung cancer in occupational populations exposed to radon and arsenic. Among occupational radon cohorts, although Colorado Plateau cohort and German uranium miners collected individual smoking data, they have not revealed the effect of smoking cessation, and other cohorts generally lacked complete smoking information (13-15). Similarly, for occupational arsenic cohorts, most epidemiological studies of copper smelters in Utah, Sweden, Montana, and the United States have not reported the role of smoking cessation on lung cancer (16-19).

Among Chinese Tin miner studies, the results from casecontrol and cohort studies for several decades have identified that radon, arsenic, and smoking are the main risk factors for lung cancer (20-22). In addition, individual exposure information about radon, arsenic, and smoking was collected in our cohort. Therefore, it provided us a unique opportunity to investigate the effect of smoking cessation on lung cancer in workers exposed to radon and arsenic.

\section{METHODS}

\section{Study Design and Participants}

The design and inclusion criteria of the Yunnan Tin Corporation (YTC) cohort was described previously $(22,23)$. Briefly, a total of 9,295 tin miners $\geq 40$ years old who had 10 or more years of underground radon and/or arsenic exposure have been dynamically included into this cohort since 1992. All participants were followed by December 31, 2018. A total of 161 former smokers who restarted smoking from 1992 to 1996 were excluded. Then, 9,134 miners were included into the final analysis to estimate the risk of lung cancer incidence according to years since smoking cessation. In addition, as 599 women in this study were almost never smokers, all women were excluded. Finally, 8,535 male miners were included into a sensitivity analysis that was used to assess the robustness of analysis (Figure 1).

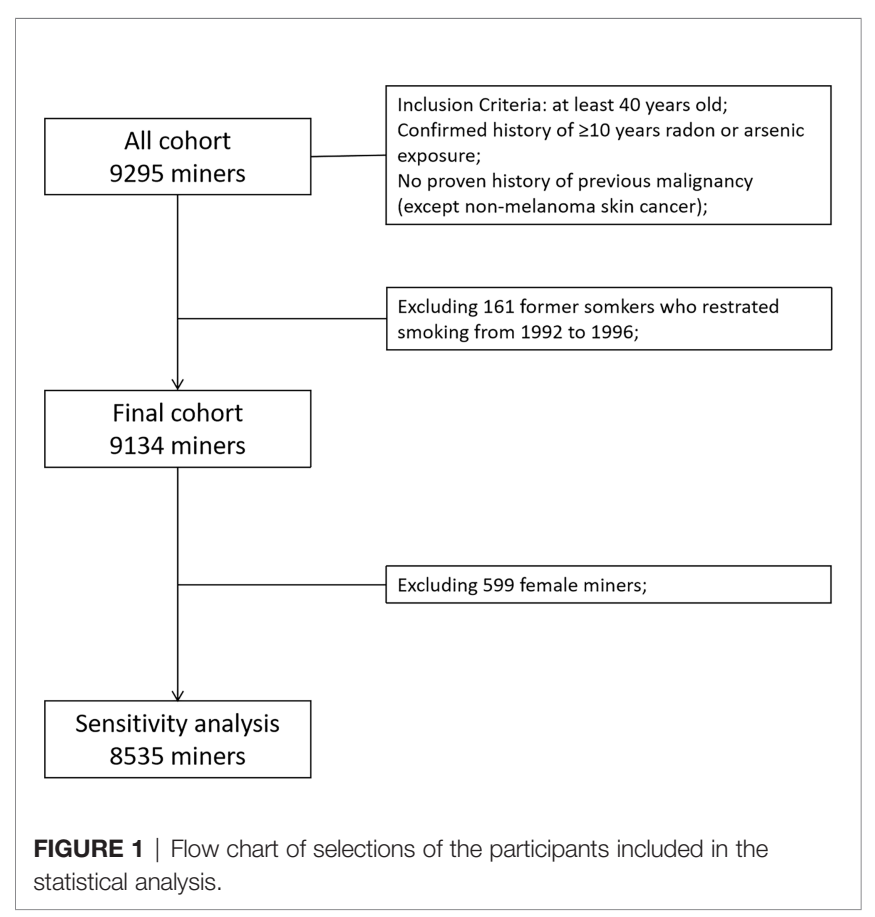




\section{Exposure Assessment Tobacco Use}

All miners were enrolled at baseline (in 1992) and information on age of start/stop smoking, type of tobacco (cigarette, waterpipe, and long-stem pipe), and smoking status was collected. According to the smoking status at baseline, we divided miners into smokers, former smokers, and never smokers. At baseline, individuals who had smoked regularly for 6 months or longer at any time in their lives were classified as smokers, and those who have a smoking duration of less than 6 months were considered never smokers and smokers who ceased smoking at enrollment were former smokers. In addition, to test the stability of smoking status, for each miner, information on smoking status and type of tobacco was collected for five consecutive years from 1992 to 1996. The change of smoking status for at least two consecutive years was identified as "the real behavior change" from 1992 to 1996. A total of 161 former smokers who restarted smoking were excluded.

However, the impact of type of cigarette was not considered in this study, because most of the participants were mixed smokers: at baseline, $62.4 \%(4,306 / 6,899)$ used cigarette + waterpipe, $29.3 \%$ $(2,022 / 6,899)$ used cigarette only, and $8.3 \%(571 / 6,899)$ used waterpipe only among current smokers; $53.6 \%(1,084 / 2,022)$ of cigarette-only and 53.6\% (306/571) of waterpipe-only smokers became mixed smokers in the next 4 years. Thus, the impact of type of cigarette was not considered in the final analysis.

Therefore, based on previous findings, we calculated a cigarette-equivalent variable adjusting conservatively: $1 \mathrm{~g}$ water pipe = 1 cigarette. Smoking intensity was measured by the number of cigarettes smoked per day and pack-years were calculated as the average number of cigarettes per day (divided by 20) times the number of years of smoking. Finally, smoking pack-years as a continuous variable was included into the multiple Cox proportional hazards model.

\section{Occupational Carcinogens}

Detailed definitions of occupational radon and arsenic exposures were given elsewhere $(22,23)$. In this study, according to total radon exposure, participants were classified into three groups: low group: $<100$ cumulative working level month (WLM), medium group: $\geq 100$ and $<400$ WLM, and high group: $\geq 400$ WLM. On the other hand, according to total arsenic exposure, participants were also classified into three groups: low group: $<40$ $\mathrm{mg} / \mathrm{m}^{3}$, medium group: $\geq 40$ and $<100 \mathrm{mg} / \mathrm{m}^{3}$, and high group: $\geq 100 \mathrm{mg} / \mathrm{m}^{3}$. Finally, we combined these groups into three new groups named occupational exposure groups: lowly exposed group: low radon group and low arsenic groups; moderately exposed group: low radon-medium arsenic, medium radon-low arsenic, and medium radon-medium arsenic; highly exposed group: either high radon group or high arsenic group (a total of 5 subgroups: low radon-high arsenic, medium radon-high arsenic, high radon-high arsenic, high radon-low arsenic, and high radon-medium arsenic). In addition, other information including age, sex, education level, and prior lung disease was also collected for each participant.

\section{Follow-Up and Case Ascertainment}

From 1992 to 1999, annual follow-up was conducted combined with screening by chest radiography and sputum cytology. In 2005 and 2006, the first post-screening follow-up was performed and participants were followed until December 31, 2001. In 2019, an extended follow-up was conducted, and the survival status, total cause of death, cancer diagnosis, and death information were collected.

The primary outcome was lung cancer incidence, which was from the local cancer registration agency, medical record system, and funeral parlor, and face-to-face interviews with relatives and workmates of the participants. In the process of information extraction, participants' name, age, work units, and home address were taken into consideration. By the end of December $31,2018,187$ participants $(2.1 \%)$ were lost to follow-up, with a follow-up rate of $97.9 \%$.

Lung cancer cases were confirmed via the following ways: (1) histology (from surgical resection tissue or biopsy); (2) cytology (from sputum sample or endoscopy brushing); (3) x-ray; and (4) others (e.g., death certificate listing only without other information).

\section{Statistical Analysis}

Person-years of follow-up were calculated from the date of enrollment to the date of lung cancer incidence or date of death or censoring as of December 31, 2018. Descriptive statistics was used to show various characteristics among never, former, and current smokers at the baseline. The association between time since smoking cessation and risk of lung cancer incidence was analyzed by the Cox proportional hazards model. Schoenfeld residuals were used to check the proportional hazards assumption. To control the effect of occupational exposures (radon and arsenic), Cox proportional hazards model was performed to calculate the hazard ratio (HR) and $95 \%$ confidence interval (95\% CI) in three different occupational exposure subgroups (low, medium, and high groups). Furthermore, to reduce potential residual confounding by occupational exposure, we also modeled occupational exposure as continuous variables into the statistical analysis within each exposed stratum. In addition, in the multiple Cox proportional hazards model, other variables including age at entry, sex, education level, family history of lung cancer in firstdegree relatives, and prior lung disease (silicosis, tuberculosis, asthma, and chronic bronchitis) were adjusted to eliminate confounding effects. Finally, since the loss of follow-up rates and missing data were very low, those with missing values were not included in the analysis. SAS and R software were used for statistical analysis.

\section{RESULTS}

The characteristics of the YTC miners in subgroups of smoking status at baseline are shown in Table 1. A total of 6,899 (75.5\%) of them were current smokers, 772 (8.5\%) were former smokers, and $1,463(16.0 \%)$ were never smokers. The number of lung 
cancer cases and person-years were 1,075 and 124,797.3 in current smokers, 121 and 12,087 in former smokers, and 128 and 30,891.0 in never smokers, respectively. Almost all women (99.7\%) were never smokers, and never smokers had the youngest age $($ mean $=49, \mathrm{IQR}=41-55)$ at enrollment. Smoking (number of pack-years in life time) in current smokers $[$ mean $=26.4$, interquartile range $(I Q R)=14.2-34.5$ ] was significantly higher than that in former smokers (mean = 18.7, IQR = 5.9-25.5). Compared with the non-smokers, current smokers had lower educational level, more prone to having prior lung disease (silicosis, tuberculosis, asthma, and chronic bronchitis), and higher occupational exposure.

The evaluation of the stability of smoking status for 5 consecutive years in the YTC cohort is shown in Table 2. From current smokers to former smokers, there were only $1.6 \%(110 / 6,899)$; from never smokers to current smokers, there were only $2.1 \%(31 / 1,463)$. Among former smokers, the stability of smoking status varied significantly with increasing years since smoking cessation: the rates of quitting successfully were $57.6 \%(68 / 118)$ in those who quit smoking at enrollment, $74.0 \%(91 / 123)$ in 1 year after quitting, $77.2 \%(129 / 167)$ in $2-5$ years after quitting, and $92.2 \%(484 / 525)$ in more than 5 years after cessation.

Table 3 shows the effects of years of smoking cessation on lung cancer incidence among miners exposed to radon and arsenic. Generally, a significantly negative gradient $(p<0.001$ for trend test) of lung cancer incidence was observed with increasing years of smoking cessation for all former smokers, despite the fact that significant risk reduction did not manifest within the first 1 year ( $\mathrm{HR}=1.03,95 \% \mathrm{CI}: 0.70-1.51), 2-5$ years $(\mathrm{HR}=0.85,95 \% \mathrm{CI}: 0.56-1.30)$, and $6-10$ years $(\mathrm{HR}=0.66,95 \%$ CI: $0.43-1.03)$ of cessation. Furthermore, the risk of lung cancer incidence was nearly halved for $10+$ years $(\mathrm{HR}=0.55,95 \% \mathrm{CI}$ : 0.38-0.79). Furthermore, we observed the effect of smoking cessation stratified by radon and arsenic exposure. Among miners from the highly exposed group, they showed similar patterns to all miners, which is shown in Table 3. Given the low sample size in the lowly and moderately exposed group, data are shown in Table $\mathbf{S 1}$ and the risk of lung cancer incidence among the lowly exposed group decreased by $50 \%$ ( $\mathrm{HR}=0.50,95 \% \mathrm{CI}$ : $0.24-1.16$ ) within 5 years since cessation, and it further decreased by $65 \%(\mathrm{HR}=0.45,95 \% \mathrm{CI}: 0.11-1.89)$ if the smokers continued

TABLE 1 | Characteristics of the YTC miners in subgroups of smoking status at baseline.

\begin{tabular}{|c|c|c|c|c|c|}
\hline \multirow[t]{2}{*}{ Characteristics } & \multirow[t]{2}{*}{ All subjects } & \multicolumn{3}{|c|}{ Smoking status at baseline } & \multirow[t]{2}{*}{$p$-value } \\
\hline & & Current smokers & Former smokers & Never smokers & \\
\hline No. of subjects & 9,134 & $6,899(75.5 \%)$ & $772(8.5 \%)$ & $1,463(16.0 \%)$ & \\
\hline Age (years) & & & & & $<0.01$ \\
\hline Mean (IQR) & $53(43-61)$ & $53(43-61)$ & $59(53-66)$ & $49(41-55)$ & \\
\hline Gender & & & & & $<0.01$ \\
\hline Male & 8,535 & 6,897 (80.8\%) & $772(9.1 \%)$ & $866(10.2 \%)$ & \\
\hline Female & 599 & $2(0.3 \%)$ & $0(0.0 \%)$ & 597 (99.7\%) & \\
\hline Education & & & & & $<0.01$ \\
\hline No & 2,155 & $1,771(82.2 \%)$ & $223(10.4 \%)$ & $161(7.4 \%)$ & \\
\hline$\leq 6$ years & 4,384 & $3,429(78.2 \%)$ & $354(8.1 \%)$ & $601(13.7 \%)$ & \\
\hline$>6$ years & 2,595 & $1,699(65.5 \%)$ & 195 (7.5\%) & $701(27.0 \%)$ & \\
\hline Family History of Lung Cancer & & & & & $<0.01$ \\
\hline Yes & 631 & 454 (71.0\%) & $40(6.3 \%)$ & 137 (21.7\%) & \\
\hline No & 8,503 & $6,445(75.8 \%)$ & $732(8.6 \%)$ & $1,326(15.6 \%)$ & \\
\hline Silicosis & & & & & $<0.01$ \\
\hline Yes & 444 & 349 (78.6\%) & 70 (15.8\%) & 25 (5.6\%) & \\
\hline No & 8,690 & $6,550(75.3 \%)$ & $702(8.1 \%)$ & $1,438(16.6 \%)$ & \\
\hline Tuberculosis & & & & & $<0.01$ \\
\hline Yes & 260 & $181(69.6 \%)$ & 40 (15.4\%) & 39 (15.0\%) & \\
\hline No & 8,874 & $6,718(75.7 \%)$ & 732 (8.2\%) & $1,424(16.1 \%)$ & \\
\hline Asthma & & & & & $<0.01$ \\
\hline Yes & 649 & 481 (74.1\%) & $119(18.3 \%)$ & $49(7.6 \%)$ & \\
\hline No & 8,485 & $6,418(75.6 \%)$ & $653(7.7 \%)$ & $1,414(16.7 \%)$ & \\
\hline Chronic bronchitis & & & & & $<0.01$ \\
\hline Yes & 2,363 & $1,856(78.5 \%)$ & $302(12.8 \%)$ & 205 (8.7\%) & \\
\hline No & 6,771 & $5,043(74.5 \%)$ & $470(6.9 \%)$ & $1,258(18.6 \%)$ & \\
\hline Pack-Years & & & & & $<0.01$ \\
\hline Mean (IQR) & $19.1(7.8-31.0)$ & $26.4(14.2-34.5)$ & 18.7 (5.9-25.5) & - & \\
\hline Occupational Exposure & & & & & $<0.01$ \\
\hline Low group & 1,143 & 690 (60.4\%) & $51(4.5 \%)$ & 402 (35.1\%) & \\
\hline Medium group & 2,998 & $2,243(74.8 \%)$ & $201(6.7 \%)$ & $554(18.5 \%)$ & \\
\hline High group & 4,993 & 3,966 (79.4\%) & $520(10.4 \%)$ & 507 (10.2\%) & \\
\hline No. of Lung Cancer & 1,324 & $1,075(81.2 \%)$ & $121(9.1 \%)$ & $128(9.7 \%)$ & \\
\hline No. of Person-Years & 167,776 & 124,797 & 12,314 & 30,891 & \\
\hline
\end{tabular}

Values were given as $n$ (\%) for categorical variables, IQR (Q1Q3): interquartile range. p-value: the differences between the proportions were tested by Chi-square test, and the mean differences were tested by ANOVA between the subgroups. Mann-Whitney $U$ test was carried out for the non-normal distribution data. 
TABLE 2 | Smoking status in five consecutive years from 1992 to 1996 in the YTC cohort.

The initial 4 years of follow-up

\begin{tabular}{|c|c|c|c|c|}
\hline & Smoking & Non-Smoking & Total & Relapse rate $(\%)^{a}$ \\
\hline \multicolumn{5}{|l|}{ At baseline } \\
\hline Current smokers & 6,789 & 110 & 6,899 & 1.6 \\
\hline Never smokers & 31 & 1,432 & 1,463 & 2.1 \\
\hline Years since cessation & & & 933 & \\
\hline$<1$ & 50 & 68 & 118 & 42.4 \\
\hline 1 & 32 & 91 & 123 & 26.0 \\
\hline $2-5$ & 38 & 129 & 167 & 22.8 \\
\hline$>5$ & 41 & 484 & 525 & 7.8 \\
\hline
\end{tabular}

${ }^{a}$ Relapse rate: During the initial 4 years offollow-up, smoking status for persistent change, that is, a change in status that remained for at least 2 years: current smokers quit, never smokers started smoking, and former smokers returned to smoking.

to abstain from cigarette smoking for 5 years or more. The beneficial effect was nearly similar in the moderately exposed group.

As most women in our cohort were never smokers, a sensitivity test had been conducted and indicated that our analysis was robust (Table S2). We further analyzed the lung cancer incidence risk in relation to years of smoking cessation by histological type among the highly exposed group, as shown in Table 4 . To reduce potential residual confounding by occupational exposure, we excluded miners in lowly and moderately exposed groups based on the quite low sample size of lung cancer cases. Results showed that for squamous cell carcinoma (SQC), the risks showed a significantly

TABLE 3 | Hazard ratio (HR, 95\% confidence interval) of lung cancer incidence according to years of smoking cessation among the YTC miners.

\begin{tabular}{|c|c|c|c|c|c|c|c|}
\hline Variable & $\begin{array}{c}\text { No. of } \\
\text { subjects }\end{array}$ & $\begin{array}{l}\text { No. of lung } \\
\text { cancer }\end{array}$ & $\begin{array}{l}\text { No. of Person- } \\
\text { Years }\end{array}$ & $\begin{array}{c}\text { No. of lung cancer/Person- } \\
\text { Years } \times 10^{4}\end{array}$ & $\begin{array}{l}\text { Crude HR } \\
\text { (95\% Cl) }\end{array}$ & $\begin{array}{l}\text { Age-/Sex-Adjusted HR } \\
(95 \% \mathrm{Cl})\end{array}$ & $\begin{array}{l}\text { Full-Adjusted HR } \\
\qquad(95 \% \mathrm{Cl})^{\mathrm{a}}\end{array}$ \\
\hline \multicolumn{8}{|c|}{ All miners without stratification } \\
\hline Never Smokers & 1,463 & 128 & $30,869.7$ & 41.5 & $\begin{array}{c}0.46(0.39 \\
0.56)\end{array}$ & $0.53(0.42,0.67)$ & $0.67(0.52,0.85)$ \\
\hline $\begin{array}{l}\text { Years since } \\
\text { cessation }\end{array}$ & 772 & 100 & $12,078.9$ & 82.8 & & & \\
\hline$\leq 1$ & 159 & 27 & $2,132.7$ & 126.6 & $\begin{array}{c}1.49(1.02 \\
2.18)\end{array}$ & $0.98(0.67,1.44)$ & $1.03(0.70,1.51)$ \\
\hline $2-5$ & 152 & 22 & $2,337.1$ & 94.1 & $\begin{array}{c}1.08(0.71 \\
1.65)\end{array}$ & $0.85(0.56,1.30)$ & $0.85(0.56,1.30)$ \\
\hline $6-10$ & 148 & 20 & $2,355.1$ & 84.9 & $\begin{array}{c}0.98(0.63 \\
1.52)\end{array}$ & $0.68(0.44,1.06)$ & $0.66(0.43,1.03)$ \\
\hline$>10$ & 313 & 31 & $5,254.0$ & 59.0 & $\begin{array}{c}0.67(0.47 \\
0.95)\end{array}$ & $0.48(0.33,0.68)$ & $0.55(0.38,0.79)$ \\
\hline $\begin{array}{l}\text { Current } \\
\text { Smokers }\end{array}$ & 6,899 & 1,096 & $124,708.7$ & 87.9 & 1 & 1 & 1 \\
\hline \multicolumn{8}{|c|}{ Highly exposed group } \\
\hline Never Smokers & 507 & 61 & $9,953.4$ & 61.3 & $\begin{array}{c}0.49(0.38 \\
0.64)\end{array}$ & $0.57(0.43,0.76)$ & $0.71(0.52,0.96)$ \\
\hline $\begin{array}{l}\text { Years since } \\
\text { cessation }\end{array}$ & 520 & 81 & $7,318.1$ & 110.7 & & & \\
\hline$\leq 1$ & 97 & 20 & $1,104.9$ & 181.0 & $\begin{array}{c}1.55(1.00 \\
2.42)\end{array}$ & $1.14(0.73,1.79)$ & $1.10(0.70,1.71)$ \\
\hline $2-5$ & 107 & 21 & $1,473.0$ & 142.6 & $\begin{array}{c}1.17(0.76 \\
1.80)\end{array}$ & $0.97(0.63,1.50)$ & $0.98(0.63,1.52)$ \\
\hline $6-10$ & 103 & 17 & $1,478.7$ & 115.0 & $\begin{array}{c}0.95(0.59 \\
1.53)\end{array}$ & $0.73(0.45,1.18)$ & $0.70(0.43,1.14)$ \\
\hline$>10$ & 213 & 23 & $3,261.6$ & 70.5 & $\begin{array}{c}0.58(0.38 \\
0.87)\end{array}$ & $0.46(0.30,0.69)$ & $0.53(0.35,0.80)$ \\
\hline $\begin{array}{l}\text { Current } \\
\text { Smokers }\end{array}$ & 3,966 & 803 & $65,478.1$ & 122.6 & 1 & 1 & 1 \\
\hline
\end{tabular}

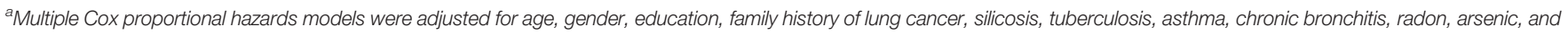

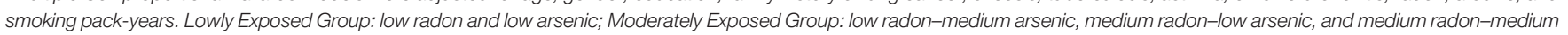

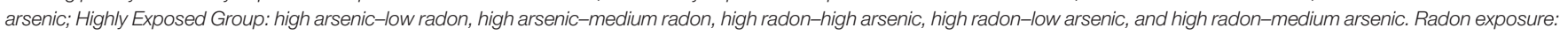

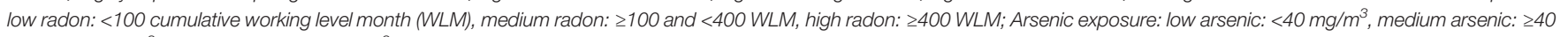
and $<100 \mathrm{mg} / \mathrm{m}^{3}$, high arsenic: $\geq 100 \mathrm{mg} / \mathrm{m}^{3}$. 
TABLE 4 | Hazard ratio (HR, 95\% confidence interval) of lung cancer incidence according to years since smoking cessation by histologic types among highly exposed group.

\begin{tabular}{|c|c|c|c|c|c|c|c|}
\hline Variable & $\begin{array}{c}\text { No. of } \\
\text { subjects }\end{array}$ & $\begin{array}{l}\text { No. of lung } \\
\text { cancer }\end{array}$ & $\begin{array}{l}\text { No. of Person- } \\
\text { Years }\end{array}$ & $\begin{array}{c}\text { No. of lung cancer/Person- } \\
\text { Years } \times 10^{4}\end{array}$ & $\begin{array}{l}\text { Crude HR } \\
\text { (95\% Cl) }\end{array}$ & $\begin{array}{l}\text { Age-/Sex-Adjusted HR } \\
(95 \% \mathrm{Cl})\end{array}$ & $\begin{array}{l}\text { Full-Adjusted HR } \\
\qquad(95 \% \mathrm{Cl})^{a}\end{array}$ \\
\hline \multicolumn{8}{|c|}{ Squamous Cell Carcinoma } \\
\hline Never Smokers & 507 & 13 & $9,953.4$ & 13.1 & $\begin{array}{l}0.34(0.20 \\
0.60)\end{array}$ & $0.51(0.29,0.89)$ & $0.56(0.32,0.99)$ \\
\hline $\begin{array}{l}\text { Years since } \\
\text { cessation }\end{array}$ & 520 & 26 & $7,318.1$ & 35.5 & & & \\
\hline$\leq 5$ & 204 & 13 & $2,577.8$ & 50.4 & $\begin{array}{c}1.24(0.71 \\
2.16)\end{array}$ & $0.94(0.54,1.65)$ & $0.92(0.52,1.61)$ \\
\hline$>5$ & 316 & 13 & $4,740.3$ & 27.4 & $\begin{array}{c}0.69(0.40 \\
1.21)\end{array}$ & $0.52(0.30,0.91)$ & $0.52(0.30,0.92)$ \\
\hline $\begin{array}{l}\text { Current } \\
\text { Smokers }\end{array}$ & 3,966 & 257 & $65,478.1$ & 39.2 & 1 & 1 & 1 \\
\hline \multicolumn{8}{|c|}{ Adenocarcinoma } \\
\hline Never Smokers & 507 & 5 & $9,953.4$ & 5.0 & $\begin{array}{c}0.37(0.15 \\
0.91)\end{array}$ & $0.55(0.22,1.35)$ & $0.72(0.28,1.89)$ \\
\hline $\begin{array}{l}\text { Years since } \\
\text { cessation }\end{array}$ & 520 & 11 & $7,318.1$ & 15.0 & & & \\
\hline$\leq 5$ & 204 & 5 & $2,577.8$ & 19.4 & $\begin{array}{c}1.47(0.60 \\
3.61)\end{array}$ & $1.12(0.45,2.77)$ & $1.16(0.47,2.89)$ \\
\hline$>5$ & 316 & 6 & $4,740.3$ & 12.7 & $\begin{array}{c}0.95(0.42 \\
2.18)\end{array}$ & $0.71(0.31,1.62)$ & $0.79(0.34,1.85)$ \\
\hline $\begin{array}{l}\text { Current } \\
\text { Smokers }\end{array}$ & 3,966 & 88 & $65,478.1$ & 13.4 & 1 & 1 & 1 \\
\hline
\end{tabular}

aMultiple Cox proportional hazards models were adjusted for age, gender, education, family history of lung cancer, silicosis, tuberculosis, asthma, chronic bronchitis, radon, arsenic, and smoking pack-years. Lowly Exposed Group: low radon and low arsenic; Moderately Exposed Group: low radon-medium arsenic, medium radon-low arsenic, and medium radon-medium arsenic; Highly Exposed Group: high arsenic-low radon, high arsenic-medium radon, high radon-high arsenic, high radon-low arsenic, and high radon-medium arsenic. Radon exposure: low radon: $<100$ cumulative working level month (WLM), medium radon: $\geq 100$ and <400 WLM, high radon: $\geq 400$ WLM; Arsenic exposure: low arsenic: $<40$ mg/m ${ }^{3}$, medium arsenic: $\geq 40$ and $<100 \mathrm{mg} / \mathrm{m}^{3}$, high arsenic: $\geq 100 \mathrm{mg} / \mathrm{m}^{3}$.

decreasing trend with increasing time since cessation $(p<0.001$ for trend test), and finally, the risk in those quitting for over 5 years was 0.52 (95\% CI: 0.30-0.92), which was similar to the risk in never smokers (HR $=0.56,95 \%$ CI: 0.32-0.99).

\section{DISCUSSION}

The YTC cohort with about 27 years of follow-up firstly reported that smoking cessation was associated with a substantial reduction in lung cancer incidence among underground miners exposed to radon and arsenic. For all lung cancer, about a $50 \%$ decrease in the risk of lung cancer incidence was shown in nearly 10 years for miners exposed to radon and arsenic. In addition, the long-term beneficial effect was weakened for adenocarcinoma, compared with squamous cell carcinoma.

In male participants among YTC miners, the risk of lung cancer among current smokers was lower than that of Western countries, Japan, Hong Kong, and the rest of mainland China (24-26). It could be due to the fact that the underground mines were relatively closed spaces and the high smoking rate of miners likely resulted in significant passive smoking exposure, even for non-smokers. Therefore, risk in non-smokers working underground in the mines was probably higher than that in non-smokers working in a less confined environment, and use of non-smokers with such exposure misclassification as a reference group would bias the relative risk estimates downward (toward the null). On the other hand, it may be that the effect of smoking is lower due to effect of these occupational exposures. Compelling evidence showed that there was a submultiplicative joint effect between occupational exposures (either radon or arsenic exposure) and smoking.

In addition, our results showed that the longer the smoking cessation time at baseline, the lower relapse rates for former smokers during the follow-up period. In cohort studies, smoking status at baseline might change over time, which resulted in bias in the true association between exposure (smoking status) and outcome (lung cancer risks). Therefore, a definition of smoking cessation with stable relapse rate was crucial in the cohort study, and our data showed that the relapse rate of quitting smoking at least $5+$ years was as low as $7.8 \%$. Because the definition of former smoker varied by study-quit smoking at least 6 months+ (27), 1+ years (28), 2+ years $(10,29,30)$, or 5+ years (9)-more studies were needed to explore the optimal definition of former smokers.

Existing lines of evidence have illustrated a definitive benefit of smoking cessation in relation to lung cancer risks. Notably, smoking cessation is associated with a decrease in relative risk of lung cancer in former smokers compared to current smokers, but the absolute lung cancer risk in former smokers does not decrease from smoking cessation. However, the temporal pattern of this risk after smoking cessation is still controversial. In a previous case-control study in Hong Kong, Lap et al. observed that compared to current smokers, there is a rapid 
decrease in lung cancer risk across most histological types of lung cancer within the first 5 years of quitting, and then it almost remained constant. However, Sadik et al. had conducted a metaanalysis and found that a continued progressive reduction in lung cancer risk resulting from smoking cessation would remain at least 15 years (31). In addition, Paul et al. had conducted a pooled analysis and found that relative risk of lung cancer to the current smokers decreased gradually and continuously over years of smoking cessation (32). Similarly, data from the Prostate, Lung, Colorectal and Ovarian Cancer Screening Trial showed that in $30+$ pack-year former smokers, smoking abstinence resulted in a gradual decrease in the risk of lung cancer death (33). Results from the National Lung Screening Trial also observed a steady decline in lung cancer death risk with the increase in duration of tobacco abstinence (34).

Generally, most epidemiological studies regarding smoking cessation and lung cancer risk were conducted in the general population, and it has been rarely investigated in occupational epidemiological studies. It appeared that this delayed decrease in lung cancer risk was more common among individuals with occupational exposure. A cohort study conducted among Australian workers exposed to asbestos found that the lung cancer mortality rate ratio among insulators dropped steeply during the first 10 years after quitting smoking (12). A large historical cohort of Chinese silicotics showed that the risk of lung cancer mortality among all silicotics was nearly halved within 20 years since cessation (adjusted HR $=0.54$, 95\% CI: 0.35-0.83) (11). It is well known that there exist joint effects between radon, arsenic, and smoking, and quitting smoking reduces not only smoking-related lung cancer, but also smoking-radon- and smoking-arsenic-related lung cancer $(13,35,36)$. However, to our knowledge, there is no study reporting the effect of smoking cessation on radon- and arsenic exposed populations. Among the YTC miners, our results firstly showed that the benefits of smoking cessation were different in occupational groups exposed to radon and arsenic. For the lowly exposed group, a rapidly decreasing lung cancer incidence risk was shown within the first 5 years of smoking cessation, which was consistent with the moderately exposed group. However, it seemed to take longer years of smoking cessation to achieve the same reduction among the highly exposed group. Importantly, findings from lowly and moderately exposed groups should be viewed as tentative given the low sample size in these two groups, and more studies would be encouraged to focus on this field in the future.

In the YTC, the risk of SQC incidence among workers highly exposed to radon and arsenic was nearly halved after 15 years or more since cessation, but the reduction was smaller for ADC. The benefit of smoking cessation was more prominent for SQC, which was consistent with findings from other studies $(10,24,27,37)$. However, a case-control study in Chinese men showed that the relative risk for SQC decreased by $78 \%$ (95\% CI: $22 \%-94 \%)$ after a smoker continued to abstain from cigarette smoking for 5 years or more (10). Therefore, it seems to be a delayed reduction of SQC among occupational populations highly exposed to radon and arsenic, compared to the general population.
The strength of this study was that it was a large, prospective population-based cohort that included detailed personal, occupational, and smoking information. There were still some limitations. The closed underground mines and the high smoking rate might have resulted in secondhand smoke exposure to nonsmokers, and further biased risk estimates downward (toward the null). Moreover, the histology information was lacking for nearly half of lung cancer cases, which would decrease the statistical power when the analysis was conducted according to histology. Finally, $4.0 \%(53 / 1,324)$ of lung cancer cases was measured by the face-toface interviews with relatives and workmates of the miners, which may be inaccurate and lead to recall bias. In this study, we had added the exposures (radon and arsenic) together without any weights, which might bias the results due to the different risks of lung cancer by radon and arsenic. Therefore, studies directly comparing the lung cancer risks from radon or arsenic should be conducted in the future.

In conclusion, our study firstly reported that among workers exposed to radon and arsenic, the benefit of smoking cessation is more related to squamous cell lung carcinoma. A tailored smoking cessation strategy is needed among the occupational population exposed to radon and arsenic.

\section{DATA AVAILABILITY STATEMENT}

The raw data supporting the conclusions of this article will be made available by the authors, without undue reservation.

\section{ETHICS STATEMENT}

The studies involving human participants were reviewed and approved by the institutional review boards of the National Cancer Center/National Clinical Research Center for Cancer/ Cancer Hospital, Chinese Academy of Medical Sciences. The patients/participants provided their written informed consent to participate in this study.

\section{AUTHOR CONTRIBUTIONS}

Y-GF and F-HZ had full access to all the data in the study and take responsibility for the integrity of the data and the accuracy of the data analysis. Conception and design: Y-LQ. Data collection: ZS and Y-GF. Analysis and interpretation: ZS. Drafting the article: ZS and X-HJ. Manuscript revision: ZS, Y-GF, and Y-LQ. All authors contributed to the article and approved the submitted version.

\section{FUNDING}

This work was supported by Cancer Foundation of China (grant No. CFC2020KYXM001) and Key R \& D projects of Science and Technology Department of Sichuan (grant No. 2020YFS0212). 
Tianjin Key Medical Discipline (Specialty) Construction Project (grant No. TJLCMS2021-02).

\section{ACKNOWLEDGMENTS}

We gratefully acknowledge all participants who have participated in this study. We thank the staff of Office of Gejiu Municipal Leading Group for Cancer Prevention and Control, Gejiu City,

\section{REFERENCES}

1. Rongshou Z, Kexin S, Siwei Z, Hongmei Z, Xiaonong Z, Ru C, et al. Analysis on the Prevalence of Malignant Tumors in China in 2015. Chin J Oncol (2019) 41:19-28. doi: 10.3760/cma.j.issn.0253-3766.2019.01.008

2. Sung H, Ferlay J, Siegel RL, Laversanne M, Soerjomataram I, Jemal A, et al. Global Cancer Statistics 2020: GLOBOCAN Estimates of Incidence and Mortality Worldwide for 36 Cancers in 185 Countries. CA: A Cancer J Clin (2021) 71(3):209-49. doi: 10.3322/caac.21660

3. Smith CJ, Perfetti TA, Rumple MA, Rodgman A, Doolittle DJ. "IARC Group 2B Carcinogens" Reported in Cigarette Mainstream Smoke. Food Chem Toxicol (2001) 39:183-205. doi: 10.1016/S0278-6915(00)00164-2

4. Fingerhut M, Nelson DI, Driscoll T, Concha-Barrientos M, Takala J. The Contribution of Occupational Risks to the Global Burden of Disease: Summary and Next Steps. La Med Del Lavoro (2006) 97:313.

5. Ramo DE, Liu H, Prochaska JJ. Tobacco and Marijuana Use Among Adolescents and Young Adults: A Systematic Review of Their Co-Use. Clin Psychol Rev (2012) 32:105-21. doi: 10.1016/j.cpr.2011.12.002

6. Li J, Li WX, Bai C, Song Y. Particulate Matter-Induced Epigenetic Changes and Lung Cancer. Clin Respir J (2017) 11:539-46. doi: 10.1111/crj.12389

7. IARC Working Group on the Evaluation of Carcinogenic Risks to Humans. Some Drinking-Water Disinfectants and Contaminants, Including Arsenic. IARC Monogr Eval Carcinog Risks Hum (2004) 84:1-477.

8. International Agency for Research on Cancer. IARC Monographs on the Evaluation of Carcinogenic Risks to Humans: Man-Made Mineral Fibres and Radon. IARC (1988) 43:1-300. Available at: https://monographs.iarc.fr/wpcontent/ uploads/2018/06/mono43.

9. Godtfredsen NS. Effect of Smoking Reduction on Lung Cancer Risk. JAMA (2005) 294:1505. doi: 10.1001/jama.294.12.1505

10. Tse LA, Yu IT, Qiu H, Au JS, Wang XR, Tam W, et al. Lung Cancer Decreased Sharply in First 5 Years After Smoking Cessation in Chinese Men. J Thorac Oncol (2011) 6:1670-6. doi: 10.1097/JTO.0b013e3182217bd4

11. Tse LA, Lin X, Li W, Qiu H, Chan CK, Wang F, et al. Smoking Cessation Sharply Reduced Lung Cancer Mortality in a Historical Cohort of 3185 Chinese Silicotic Workers From 1981 to 2014. Br J Cancer (2018) 119:1557-62. doi: 10.1038/s41416-018-0292-6

12. Markowitz SB, Levin SM, Miller A, Morabia A. Asbestos, Asbestosis, Smoking, and Lung Cancer. New Findings From the North American Insulator Cohort. Am J Respir Crit Care Med (2013) 188:90-6. doi: 10.1164/rccm.201302-0257OC

13. National Research Council. Health Effects of Exposure to Radon: BEIR VI. Washington, DC: National Academies Press (1999). Available at: https://doi. org/10.17226/5499.

14. Mary K, Schubauer-Berigan RDD, Pinkerton LE. Radon Exposure and Mortality Among White and American Indian Uranium Miners: An Update of the Colorado Plateau Cohort. Am J Epidemiol (2009) 169:71830. doi: 10.1093/aje/kwn406

15. Kreuzer M, Fenske N, Schnelzer M, Walsh L. Lung Cancer Risk at Low Radon Exposure Rates in German Uranium Miners. Brit J Cancer (2015) 113 (9):1367-9. doi: 10.1038/bjc.2015.324

16. Rencher AC, Carter MW, Mckee DW. A Retrospective Epidemiological Study of Mortality at a Large Western Copper Smelter. J Occup Environ Med (1977) 19(11):754-8.

17. Pershagen G, Wall S, Taube A, Linnman L. On the Interaction Between Occupational Arsenic Exposure and Smoking and its Relationship to Lung Cancer. Scand J Work Environ Health (1981) 7(4):302-9. doi: 10.5271/sjweh.2544
Yunnan, China for their assistance in the collection of the followup data of the YTC cohort.

\section{SUPPLEMENTARY MATERIAL}

The Supplementary Material for this article can be found online at: https://www.frontiersin.org/articles/10.3389/fonc.2022.817045/ full\#supplementary-material

18. Enterline PE, Marsh GM, Esmen NA, Henderson VL, Paik M. Some Effects of Cigarette Smoking, Arsenic, and SO2 on Mortality Among US Copper Smelter Workers. J Occup Med (1987) 29:831-8.

19. Järup L, Pershagen G. Arsenic Exposure, Smoking, and Lung Cancer in Smelter Workers-A Case-Control Study. Am J Epidemiol (1991) 134:545-51. doi: 10.1093/oxfordjournals.aje.a116128

20. Qiao YL, Taylor PR, Yao SX, Schatzkin A, Mao BL, Lubin J, et al. Relation of Radon Exposure and Tobacco Use to Lung Cancer Among Tin Miners in Yunnan Province, China. Am J Ind Med (1989) 16:511-21. doi: 10.1002/ajim.4700160504

21. Taylor PR, Qiao YL, Schatzkin A, Yao SX, Lubin J, Mao BL, et al. Relation of Arsenic Exposure to Lung Cancer Among Tin Miners in Yunnan Province, China. Br J Ind Med (1989) 46:881-6. doi: 10.1136/oem.46.12.881

22. Qiao YL, Taylor PR, Yao SX, Erozan YS, Luo XC, Barrett MJ, et al. Risk Factors and Early Detection of Lung Cancer in a Cohort of Chinese Tin Miners. Ann Epidemiol (1997) 7:533-41. doi: 10.1016/S1047-2797(97)00115-4

23. Taylor PR, Qiao YL, Schatzkin A, Yao SX, Lubin J, Mao BL, et al. Relation of Arsenic Exposure to Lung Cancer Among Tin Miners in Yunnan Province, China. Occup Environ Med (1989) 46:881-6. doi: 10.1136/oem.46.12.881

24. Pesch B, Kendzia B, Gustavsson P, Jöckel KH, Johnen G, Pohlabeln H, et al. Cigarette Smoking and Lung Cancer-Relative Risk Estimates for the Major Histological Types From a Pooled Analysis of Case-Control Studies. Int J Cancer (2012) 131:1210-9. doi: 10.1002/ijc.27339

25. Seki T, Nishino Y, Tanji F, Maemondo M, Takahashi S, Sato I, et al. Cigarette Smoking and Lung Cancer Risk According to Histologic Type in Japanese Men and Women. Cancer Sci (2013) 104:1515-22. doi: 10.1111/cas.12273

26. Chen ZM, Peto R, Iona A, Guo Y, Chen YP, Bian Z, et al. Emerging TobaccoRelated Cancer Risks in China: A Nationwide, Prospective Study of 0.5 Million Adults. Cancer (2015) 121 Suppl 17:3097-106. doi: 10.1002/cncr.29560

27. Pohlabeln H, Jöckel KH, Müller KM. The Relation Between Various Histological Types of Lung Cancer and the Number of Years Since Cessation of Smoking. Lung Cancer (1997) 18:223-9. doi: 10.1016/S0169-5002(97)00067-6

28. Leitzmann MF, Koebnick C, Abnet CC, Freedman ND, Park Y, Hollenbeck A, et al. Prospective Study of Physical Activity and Lung Cancer by Histologic Type in Current, Former, and Never Smokers. Am J Epidemiol (2009) 169:542-53. doi: 10.1093/aje/kwn371

29. Crispo A, Brennan P, Jöckel KH, Schaffrath-Rosario A, Wichmann HE, Nyberg F, et al. The Cumulative Risk of Lung Cancer Among Current, Exand Never-Smokers in European Men. Br J Cancer (2004) 91:1280-6. doi: 10.1038/sj.bjc.6602078

30. Mei Z, Wang L-M, Chong LY, Li X-Y, Yong J, Nan H, et al. A 2010 Survey on Smoking and Cessation Behaviors Among Chinese Adults. Chin J Prev Med (2012) 46(5):404-8. doi: 10.3760/cma.j.issn.0253-9624.2012.05.006

31. Putter H, Fiocco M, Geskus RB. Tutorial in Biostatistics: Competing Risks and Multi-State Models. Stat Med (2007) 26:2389-430. doi: 10.1002/sim.2712

32. Wakai K, Marugame T, Kuriyama S, Sobue T, Tamakoshi A, Satoh H, et al. Decrease in Risk of Lung Cancer Death in Japanese Men After Smoking Cessation by Age at Quitting: Pooled Analysis of Three Large-Scale Cohort Studies. Cancer Sci (2007) 98:584-9. doi: 10.1111/j.1349-7006.2007.00423.x

33. Pinsky PF, Zhu CS, Kramer BS. Lung Cancer Risk by Years Since Quitting in 30+ Pack Year Smokers. J Med Screen (2015) 22:151-7. doi: 10.1177/ 0969141315579119

34. Tanner NT, Kanodra NM, Gebregziabher M, Payne E, Halbert CH, Warren GW, et al. The Association Between Smoking Abstinence and Mortality in the National Lung Screening Trial. Am J Respir Crit Care Med (2016) 193:534-41. doi: 10.1164/rccm.201507-1420OC 
35. Lubin JH, Boice JD Jr., Edling C, Hornung RW, Howe GR, Kunz E, et al. Lung Cancer in Radon-Exposed Miners and Estimation of Risk From Indoor Exposure. J Natl Cancer Inst (1995) 87:817-27. doi: 10.1093/jnci/87.11.817

36. Su Z, Wei M-N, Jia X-H, Fan Y-G, Zhao F-H, Zhou Q-H, et al. Arsenic, Tobacco Use, and Lung Cancer: An Occupational Cohort With 27 Follow-Up Years. Environ Res (2021) 206:112611. doi: 10.1016/j.envres.2021.112611

37. Khuder SA, Mutgi AB. Effect of Smoking Cessation on Major Histologic Types of Lung Cancer. Chest (2001) 120:1577-83. doi: 10.1378/chest.120.5.1577

Conflict of Interest: The authors declare that the research was conducted in the absence of any commercial or financial relationships that could be construed as a potential conflict of interest.
Publisher's Note: All claims expressed in this article are solely those of the authors and do not necessarily represent those of their affiliated organizations, or those of the publisher, the editors and the reviewers. Any product that may be evaluated in this article, or claim that may be made by its manufacturer, is not guaranteed or endorsed by the publisher.

Copyright (C) 2022 Su, Jia, Zhao, Zhou, Fan and Qiao. This is an open-access article distributed under the terms of the Creative Commons Attribution License (CC BY). The use, distribution or reproduction in other forums is permitted, provided the original author(s) and the copyright owner(s) are credited and that the original publication in this journal is cited, in accordance with accepted academic practice. No use, distribution or reproduction is permitted which does not comply with these terms. 